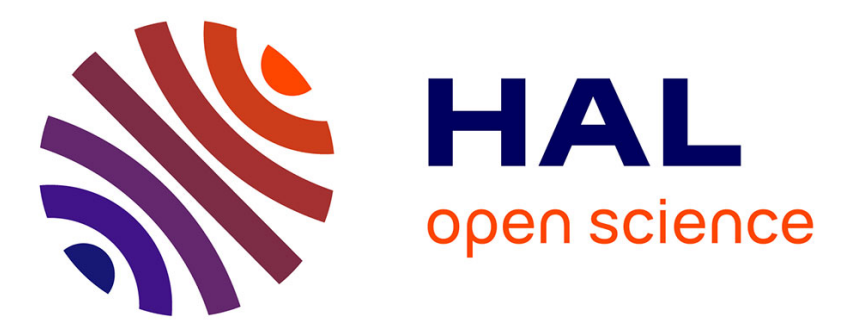

\title{
Polyp longevity in a precious gorgonian coral: hints toward a demographic approach to polyp dynamics
}

Maria Carla Benedetti, Lorenzo Bramanti, Cristina Priori, Fabrizio Erra, Mimmo Iannelli, Fabio Bulleri, Giovanni Santangelo

\section{To cite this version:}

Maria Carla Benedetti, Lorenzo Bramanti, Cristina Priori, Fabrizio Erra, Mimmo Iannelli, et al.. Polyp longevity in a precious gorgonian coral: hints toward a demographic approach to polyp dynamics. Coral Reefs, 2020, 39 (4), pp.1125-1136. 10.1007/s00338-020-01942-6 . hal-02927645

\section{HAL Id: hal-02927645 \\ https://hal.sorbonne-universite.fr/hal-02927645}

Submitted on 24 Nov 2020

HAL is a multi-disciplinary open access archive for the deposit and dissemination of scientific research documents, whether they are published or not. The documents may come from teaching and research institutions in France or abroad, or from public or private research centers.
L'archive ouverte pluridisciplinaire HAL, est destinée au dépôt et à la diffusion de documents scientifiques de niveau recherche, publiés ou non, émanant des établissements d'enseignement et de recherche français ou étrangers, des laboratoires publics ou privés. 


\section{Polyp longevity in a precious gorgonian coral: hints toward 3 a demographic approach to polyp dynamics}

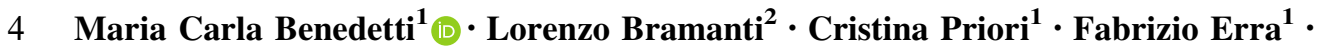

5 Mimmo Iannelli ${ }^{3} \cdot$ Fabio Bulleri $^{1} \cdot$ Giovanni Santangelo $^{1}$

A7

A9
Received: 12 December 2018/ Accepted: 24 April 2020

(C) Springer-Verlag GmbH Germany, part of Springer Nature 2020

\begin{abstract}
In this paper, we investigated the age distribution and dynamics of polyps in the slow-growing and longlived gorgonian Corallium rubrum (the Mediterranean red coral), applying an a posteriori demographic approach by considering each colony as a population of polyps. In the Mediterranean red coral, new polyps emerge from the coenenchyme in different regions of the colony and their budding rate depends on the age of branches. The age of polyps, branches and colonies were estimated using the organic-matter-staining dating method on thin sections of the colony skeleton. The median age and maximum life span of polyps were 4 and 12 years suggesting the presence of senescence processes: thus a colony renews several times its polyps during life cycle. Polyps were divided into annual age classes, and their mortality rates calculated. The polyp age distribution was then used to construct a mortality table and an algebraic transition matrix based on the age at death of 234 polyps. Finally, the polyp budding rate of a young, unbranched colony was calculated, and polyp temporal dynamics simulated. These findings represent the
\end{abstract}

Topic Editor Andrew Hoey

Electronic supplementary material The online version of this article (https://doi.org/10.1007/s00338-020-01942-6) contains supplementary material, which is available to authorized users.

Maria Carla Benedetti

carlottabenedetti88@hotmail.it

1 Department of Biology, University of Pisa, CoNISMa, Via Volta 6, 56126 Pisa, Italy

2 Sorbonne Université, CNRS, Laboratoire d'Ecogéochimie des Environnements Benthiques, LECOB, 66650 Banyuls-sur-Mer, France

3 Department of Mathematics, University of Trento, Via Sommarive 14, 38123 Povo, TN, Italy first steps for developing demographic models able to describe polyp dynamics of old and highly branched colonies.

Keywords Octocoral · Polyp age $\cdot$ Mortality table · Budding rate

\section{Introduction}

Modularity is a common feature among plants and invertebrates. Nowadays, the term modular is mainly used as synonymous of hierarchical and refers to the repetition of homogenous units at different organization levels (Rosen 1986; Kim and Lasker 1998; Hageman 2003). The first definition of corals as modular organisms can be found in Harper (1977). Polyps, embedded in the coenenchyme, are the primary modules of colonial corals. They are the basic units of a colony, likely determining its shape by regulating the growth of branches (second-order modules, called structural units, Hageman et al. 1998; Hageman 2003). Therefore, the fundamental body plan of a colonial coral, often characterized by different growth forms, results from the repetition of units, i.e. polyps and branches of several orders and varying lengths (Williams 1975; Harper 1977; Harper and Bell 1979; Burlando et al. 1991; Lasker et al. 2003; Sánchez and Lasker 2003; Sánchez et al. 2004; Goffredo and Lasker 2006).

Morphological plasticity, typical of modular organisms, is likely the result of genotypic variability or phenotypic response to local environmental conditions (e.g., Shaish et al. 2006, 2007; Sánchez et al. 2007; Rowley et al. 2015; Guizien and Ghisalberti 2017). The optimal shape of a stony-coral colony is the result of the polyp ability to calcify (Matsumoto 2004; Goffredo and Lasker 2006) and

$\begin{array}{lll}\text { Journal : Large 338 } & \text { Dispatch : 18-5-2020 } & \text { Pages : 12 } \\ \text { Article No. : } \mathbf{1 9 4 2} & \square \text { LE } & \square \text { TYPESET } \\ \text { MS Code : CORE-D-18-00305R3 } & \sim_{\text {CP }} & \checkmark \text { DISK }\end{array}$


can thus be affected by polyp distribution and density (Rossi et al. 2019). For example, ramified gorgonians have evolved a prey capture structure by which barbed tentacles of polyps and branches form an efficient fishing net intercepting water flow thus feeding on detrital particulate organic matter (POM) and microplankton (Barham and Davies 1968; Grigg 1972; Russo 1985; Coma et al. 2001; Kaandorp and Küler 2001; Tsounis et al. 2006b; Picciano and Ferrier-Pagès 2007; Pedoni et al. 2009; Gori et al. 2011).

Merks et al. (2004) described coral growth as the "collective result of a growth process taking place in the polyps." In their "polyp-oriented model," polyps are considered as separate units, which during their life cycle deposit skeleton, bud new polyps and eventually die. Each colony can then be considered as a population of polyps and branches (belonging to the same genet; Harper 1977; Galli et al. 2016); thus, its growth over time can be projected by dynamic models based on polyp growth and mortality rates, as well as increase in branch number. Under these circumstances, integrating data from individual and modular growth studies may enhance the understanding of growth in highly plastic corals. Precious corals belonging to the Family Corallidae are generally slowgrowing and long-lived, thus, following their growth over the entire life span is a nearly impossible task (Santangelo et al. 2003) and indirect methods to assess colony development in these species are needed (Marschal et al. 2004; Vielzeuf et al. 2008; Benedetti et al. 2016; Kahramanoğullari et al. 2019).

We investigated polyp formation, age and spatial distribution in the highly valuable octocoral Corallium rubrum (L 1758; Fig. 1), considering the iteration of the primary modules (polyps) as the lowest level of colony organization. C. rubrum is a long-lived Mediterranean gorgonian, whose life span can exceed a century (Marschal et al. 2004; Priori et al. 2013). This species is endemic to the Mediterranean Sea and neighboring Atlantic rocky bottoms, where it dwells between 10 and $1000 \mathrm{~m}$ depth. Within this wide bathymetric distribution, shallow $(<50 \mathrm{~m})$, deep $(50-200 \mathrm{~m})$, and deeper populations $(>200 \mathrm{~m}$ ) have been conventionally distinguished by an operative point of view (Santangelo and Abbiati 2001; Costantini et al. 2011; Knittweis et al. 2016). C. rubrum has long been subjected to commercial fishing, as its red calcareous skeleton is widely used in jewelry and traded worldwide (e.g., Cicogna and Cattaneo-Vietti 1993; Tsounis et al. 2010). Due to its slow growth rates ( $\sim 0.24 \mathrm{~mm} \mathrm{y}^{-1}$ in basal diameter; Marschal et al. 2004; Priori et al. 2013; Bramanti et al. 2014; Benedetti et al. 2016), the overharvesting of larger/older colonies has caused an alarming shift in the structure of existing populations toward smaller sizes (Santangelo and Abbiati
2001; Tsounis et al. 2006a; Bramanti et al. 2009; Cau et al. 2016; Garrabou et al. 2017). C. rubrum has therefore been included in three different international conventions (EU Directive Habitat, Bern Convention, and Convention on Biological Diversity) and its harvesting is regulated by Mediterranean, national and local/regional rules (GFCMFAO 2011). For species with long life span and complex life cycle such as $C$. rubrum demographic studies are required to advise policy makers on the most appropriate conservation and management strategies (Santangelo et al. 2007; Bramanti et al. 2009).

A first step to assess population demographic dynamics is estimating the age of its components (Bramanti et al. 2017). Age distribution data can be used for developing life history tables and for projecting population trends over time by means of algebraic transition matrices (Caswell 2001; Fujiwara and Caswell 2001; Santangelo et al. 2015).

In this paper, we scale this approach down from the population to the colony level, considering a single colony as a population of polyps. While several studies have dealt with aging in octocorals (e.g., Sherwood 2006; Thresher et al. 2009), little is known about the aging and life span of polyps. We applied a novel method for assessing the age of Mediterranean red coral polyps (Vielzeuf et al. 2008) and their turnover to build a life history table (mortality table). In order to estimate the budding rate of polyps in a young colony and to project its structure through time, a transition matrix of polyp survival was constructed by means life history data. Thus, our work focuses on: (1) early skeleton formation and dynamics of polyp number, (2) distribution of polyp age and density across the colony, (3) polyp life span, mortality and variations in budding rate through time.

\section{Materials and methods}

\section{C. rubrum basic features}

The Mediterranean red coral is gonochoric at both the polyp and colony levels and is characterized by a long life span and an early age at first reproduction (Santangelo et al. 2003; Gallmetzer et al. 2010). It is an internal brooder whose larvae are released yearly in late summer and settle within 20-25 days (L Bramanti personal observ.). After settlement, metamorphosis occurs in approximately 10 days (L Bramanti pers. observ.) and a new colony starts growing (Lacaze Duthiers 1864; Vighi 1972).

Similarly to other colonial octocorals, C. rubrum has polyps embedded in the coenenchyme, and their gastrovascular cavities are interconnected by superficial and deep gastrodermal channels (Lacaze Duthiers 1864). The

$\begin{array}{lll}\text { Journal : Large } 338 & \text { Dispatch : 18-5-2020 } & \text { Pages : 12 } \\ \text { Article No. : } \mathbf{1 9 4 2} & \square \text { LE } & \square \text { TYPESET } \\ \text { MS Code : CORE-D-18-00305R3 } & \sim_{\text {CP }} & \checkmark \text { DISK }\end{array}$


Fig. 1 a Corallium rubrum colonies in the Marine Protected Area of Cerbere/Banyuls sur Mer (L Bramanti photocredits); b A colony depleted of coenechyme (arrows indicate polyp cavity marks) and a detail of crenulated colony axis with a polyp cavity mark without crenulations. c Three types of branches in a C. rubrum colony; d Thin OMS section of colony axis where annual growth rings are highlighted. Three dead (black rectangles) and one living polyp cavity mark (white rectangle) are shown
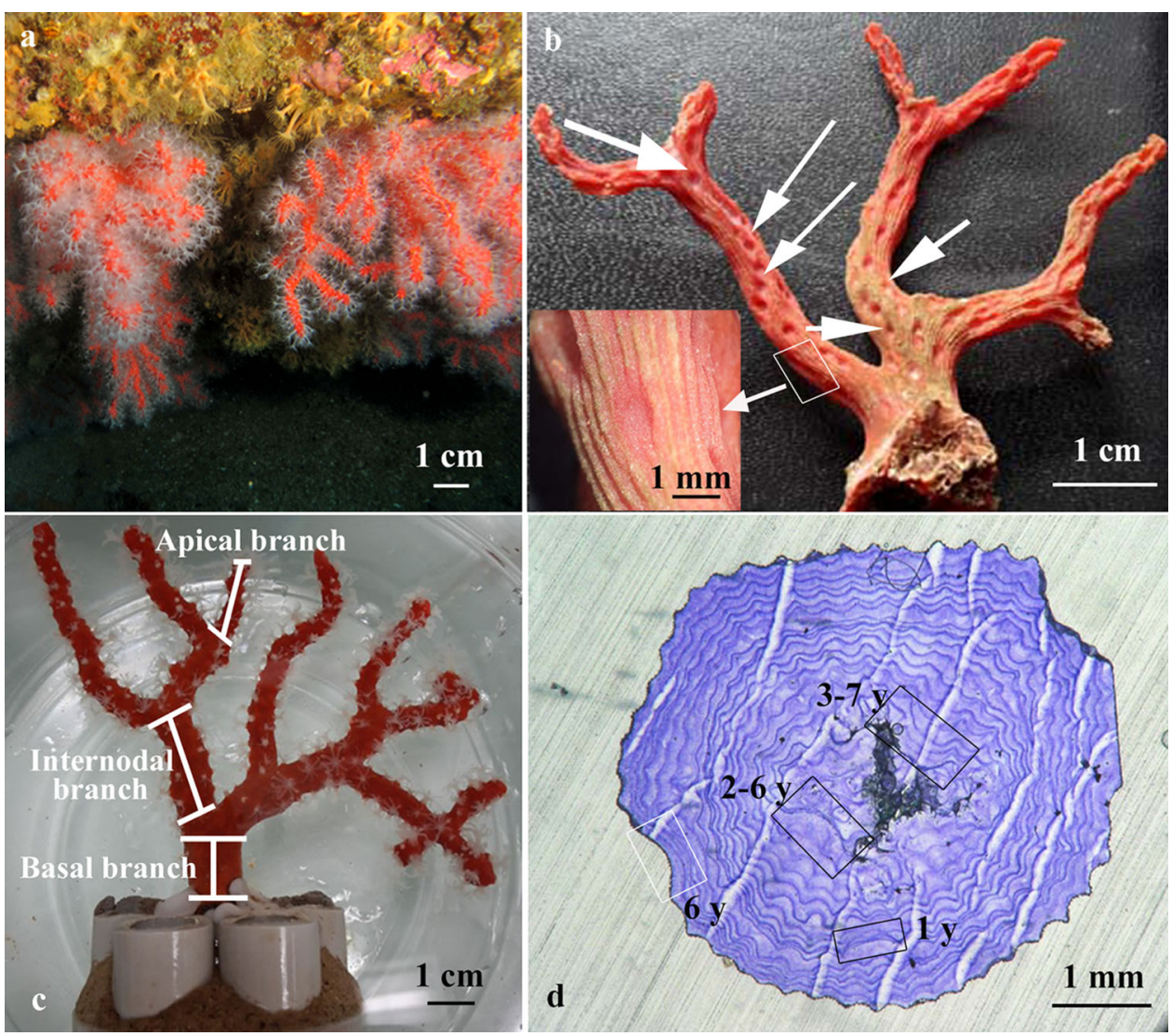

superficial channels are small and located within the coenenchyme layer, while the deep channels are larger and located in crenulations (wavelets) along the skeleton surface. When the coenenchyme and polyps are removed, a cavity mark can be distinguished, imprinted on the skeleton just below the polyp (Fig. 1b; Lacaze Duthiers 1864; Grillo et al. 1993; Vielzeuf et al. 2008). The deep channels are absent on the surface of these cavity marks, hence no crenulations are found below the polyps (Fig. 1b; Perrin et al. 2015).

\section{Skeleton formation and dynamics of polyp number}

The early skeleton formation in 1-4-year-old colonies (settled on artificial substrates; see Bramanti et al. 2005, 2007) has been examined under a dissection microscope (40-60 x; Fig. 2).

The relationship between total number of polyps and branches was tested on 518 intact colonies of different size (out of 695 collected across the Northwestern Mediterranean between 2009 and 2016; Priori et al. 2013; Bramanti et al. 2014; Benedetti et al. 2016; unfortunately no environmental data on sampling sites was at our disposal (sampling details in Supplemental Materials). All the colonies were photographed, numbered and fixed in $4 \%$ formalin for laboratory analysis. The total number of polyps and the sex of each colony were determined under a binocular dissecting microscope (Santangelo et al. 2003).

Three types of branches were identified in each colony: basal, internodal and apical. The basal branch corresponds to the base of the colony, the internodal branch is the first branch generated by the branching process (i.e., the largest/ oldest branch of the colony; Benedetti et al. 2016) and the apical branch was chosen randomly among the tips (Fig. 1c).

The relationship between the number of apical branches and the number of polyps was assessed by means of linear, power, logarithmic and exponential fits and the one with the highest $R^{2}$ was selected. Significance was tested by Pearson's correlation coefficient on $\log / \log$ transformed data.

\section{Polyp age and distribution}

The age of polyps was estimated by applying the procedure developed by Vielzeuf et al. (2008) based on the Organic Matrix Staining (OMS) method for colony dating (Marschal et al. 2004), which highlights annual growth rings on decalcified and stained thin sections $(50 \mu \mathrm{m})$, transversal to colony axis. Only 135 colonies (out of 695) were suitable for this analysis (i.e., without signs of damage by boring sponges). Overall, 197 transverse thin sections cut
186

$\begin{array}{lll}\text { Journal : Large 338 } & \text { Dispatch : 18-5-2020 } & \text { Pages : 12 } \\ \text { Article No. : } \mathbf{1 9 4 2} & \square \text { LE } & \square \text { TYPESET } \\ \text { MS Code : CORE-D-18-00305R3 } & \cup_{\text {CP }} & \sim_{\text {DISK }}\end{array}$


Fig. 2 Formation of C. rubrum skeleton starting from the walls of cavity marks: a Young colony at 1 polyp-stage (L Bramanti photocredits). b Skeleton of the colony at this stage. c Young colony at 2 polyp-stage. (after Lacaze Duthiers 1864). d Skeleton of the colony at this stage. e Skeleton of a young colony at 4 polyp-stage. f Skeleton of a 2-3-year-old colony: this " $x$ profile" will form the central core in older colonies. $\mathrm{g}$ Thin section of an older colony axis: the central core is highlighted by the arrow
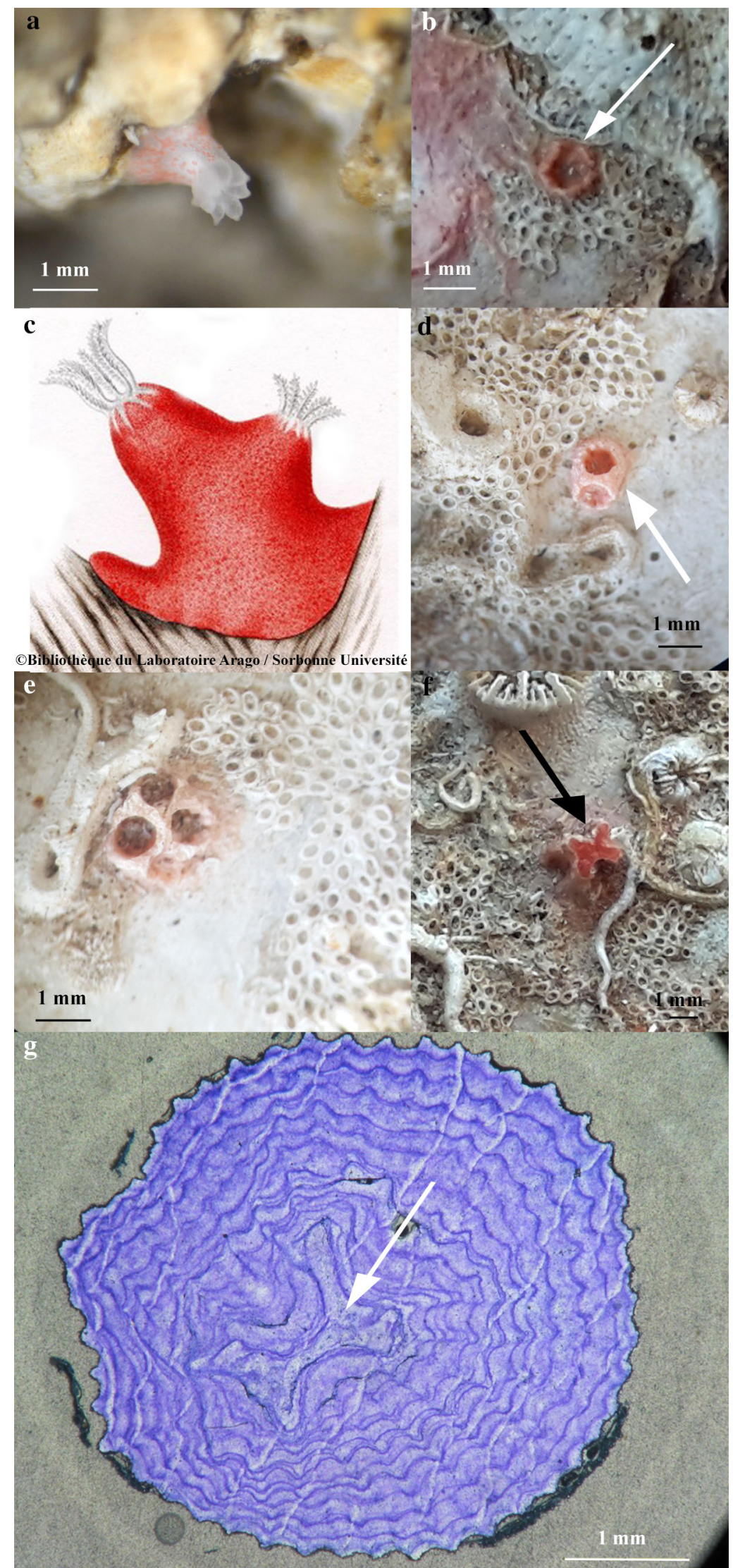

\begin{tabular}{|l|lll|}
\hline Journal : Large 338 & Dispatch : 18-5-2020 & Pages : 12 \\
Article No. : $\mathbf{1 9 4 2}$ & $\square$ LE & $\square$ TYPESET \\
MS Code : CORE-D-18-00305R3 & $\sim_{\mathrm{CP}}$ & $\boldsymbol{\sim}$ DISK \\
\hline
\end{tabular}


along the branches (135 basal sections and 62 internodal and apical sections) were stained and examined to identify the locations of polyps (i.e., cavity marks) and to estimate their age. On thin sections, each annual growth ring is made up of two seasonal bands (light and dark), with crenulations in correspondence to the deep gastrodermal channels (Fig. 1b, d). As these channels are absent on the cavity mark surface, the lack of the crenulated layer along growth rings indicates the presence of a polyp, and the number of non-crenulated growth rings gives an estimate of polyp age (Fig. 1d; Vielzeuf et al. 2008). A cavity mark where the non-crenulated layer reaches the most external growth ring (i.e., the most recent) indicates a polyp that was still alive at the time of colony collection. When such a marker was not present in the last growth ring (Fig. 1d), we assumed that the polyp was already dead at the time of collection (hereafter called "past polyp"). Polyps still alive at the time of sampling were excluded from the calculation of longevity and life span.

The mean number of living and past polyp marks were divided according to the age of the colony at the level at which the thin section was cut. The age of branches was determined by applying the OMS method $(n=162)$.

As data were not normally distributed, a nonparametric analysis (Mann-Whitney) was applied to test if polyp age differs between females $(n=82)$ and males $(n=93)$, and between shallow $(n=168)$ and deep $(n=63)$ populations.

The average width of polyp cavity marks (i.e., the linear distance between the two edges of the depression), measured on the most evident cavities $(n=114)$, was used as a proxy for polyp diameter. Polyp growth rates $\left(\mathrm{mm} \mathrm{y}^{-1}\right)$ were then calculated as the ratio between cavity mark width and polyp age.

The density of polyps was measured on 10 living colonies maintained alive in aquaria at $17 \pm 1^{\circ} \mathrm{C}$ (sampling details in Supplemental Materials). The number of polyps on the three branch types (basal $n=10$, internodal $n=10$ and apical $n=10$ ) was counted under a dissecting microscope. For accuracy, polyp counts were performed twice, and the average value was used for the analysis. The length (distance, in $\mathrm{mm}$, between the branch base and tip) and mean diameter (in $\mathrm{mm}$, at the branch base and tip) of each branch on the colony skeletons were measured with calipers and the branch surface $\left(\mathrm{cm}^{2}\right)$ was calculated by approximating their shape to a truncated cone. Polyp density (number $\times \mathrm{cm}^{-2}$ ) was calculated by dividing the polyp number by the area of each branch. In order to account for autocorrelation of data within a colony, polyp density in different branches of colonies was analyzed using a linear mixed model, including the branch types as a fixed effect and the colony as a random effect (model $<-\operatorname{lmer}($ Density $\sim$ Branchtypes $+(1 \mathrm{lCol}-$ ony)), using the function 'Imer' in the R package 'Ime4' (Bates et al. 2015). In order to assess the fit of the model, we calculated the marginal and conditional $R^{2}$, using the function r.squared GLMM in the package MuMIn (Barton 2019). The marginal $R^{2}$ provides an estimate of the proportion of total variance explained by the fixed factor alone, while the conditional $R^{2}$ an estimate of that explained by both the fixed and random factors (Nakagawa and Schielzeth 2013). We tested the effects of Branch Type in the linear mixed model with a Type-III ANOVA (Table 1), using Satterthwaite's method (lmerTest package; Kuznetsova et al. 2017). The function 'lsmeans' in the R package 'Ismeans' (Lenth 2016) was used for post hoc comparisons among Branch Type levels. Assumptions of linearity and homogeneity of variance were checked by means of Q-Q plots and by plotting residuals versus fitted values.

\section{Mortality table and budding rate}

Based on the age of past polyps, a mortality table was constructed (i.e., a life table based on the age of polyps at death; Bergher 1990; Arrigoni et al. 2011; Table 2). In this
Table 1 (a) Type-III ANOVA of polyp density. (b) Post hoc comparisons among Branch Type levels

\begin{tabular}{lllllll}
\hline a) & & & & & \\
\hline & Sum Sq & Mean Sq & Num DF & Den DF & $F$ value & $\operatorname{Pr}(>F)$ \\
\hline Branch Type & 325.91 & 162.96 & 2 & 18 & 10.344 & 0.001022 \\
\hline
\end{tabular}

(b)

\begin{tabular}{lccccc}
\hline Contrast & Estimate & SE & DF & $t$ ratio & $p$ value \\
\hline Apical-basal branches & 8.06 & 1.78 & 18 & 4.541 & 0.0007 \\
$\begin{array}{l}\text { Apical-internodal } \\
\text { branches }\end{array}$ & 4.43 & 1.78 & 18 & 2.494 & 0.0560 \\
$\begin{array}{l}\text { Basal- internodal } \\
\text { branches }\end{array}$ & -3.63 & 1.78 & 18 & -2.047 & 0.1298 \\
\hline
\end{tabular}

$\begin{array}{lll}\text { Journal : Large } 338 & \text { Dispatch : 18-5-2020 } & \text { Pages : 12 } \\ \text { Article No. : } \mathbf{1 9 4 2} & \square \text { LE } & \square \text { TYPESET } \\ \text { MS Code : CORE-D-18-00305R3 } & \checkmark_{\text {CP }} & \checkmark \text { DISK }\end{array}$


table, polyps were divided into yearly age classes, and the number of dead $\left(X_{i}\right)$ and survivors $\left(S_{i}\right)$ during each age interval reported.

Mortality values were used to construct a survival transition matrix (Table 3), in which the nonzero entries in the lower diagonal are the probabilities $\left(\sigma_{i}\right)$ of polyp survival from one age class $(i)$ to the next $(i+1)$. The data presented in Tables 2 and 3 were used to develop a model describing the polyp budding rate in a young, unbranched colony; as this rate is most likely similar to that of a new branch, this parameter will hereafter be referred to as "branch budding rate." Then, the polyp number at the colony base was projected over a period of 50 years. A detailed description of the model and calculations of budding rate variability are reported in the Supplemental Materials.

\section{Results}

\section{Skeleton formation and dynamics of polyp number}

The early formation of the skeleton was described on the basis of the observation of polyp cavity marks in 1-4-yearold colonies. A few weeks after larval settlement, the new whitish polyp starts to deposit sclerites in the coenosarc, forming the first cavity of the primary polyp (L Bramanti personal observations; Fig. 2a, b). After two months, when the young colony has two polyps (Fig. 2c), two adjacent cavities are visible in the skeleton (Fig. 2d). Four cavities from a quartet of adjacent polyps were evident in 1-yearold colony skeletons (Fig. 2e). During the first 4 years, only the skeleton between adjacent cavities grows and form an "x-shaped profile" (from a vertical point of view, Fig. 2f), which becomes the butterfly-like structure observed in the transversal sections of the central skeletal core of $>4$ years old colonies (arrow in Fig. $2 \mathrm{~g}$ ).

In branched colonies, older than 10 years, there was no relationship between colony age and polyp number. However, a significant, correlation described by a power function was found between the number of polyps in a colony and the number of its apical branches $\left(y=23.87 x^{0.91}\right.$, $R^{2}=0.62, p<0.01, n=548$; Fig. 3 ). This suggests that the total number of polyps is linked to the number of branches rather than to colony age.

\section{Polyp age and distribution}

A total of 197 transversal sections of $C$. rubrum skeletons were examined and 355 polyp cavity marks identified ( 234 of past polyps and 121 of polyps that were still alive at the time of colony collection). Living polyps were more abundant in sections cut from the younger branches of a

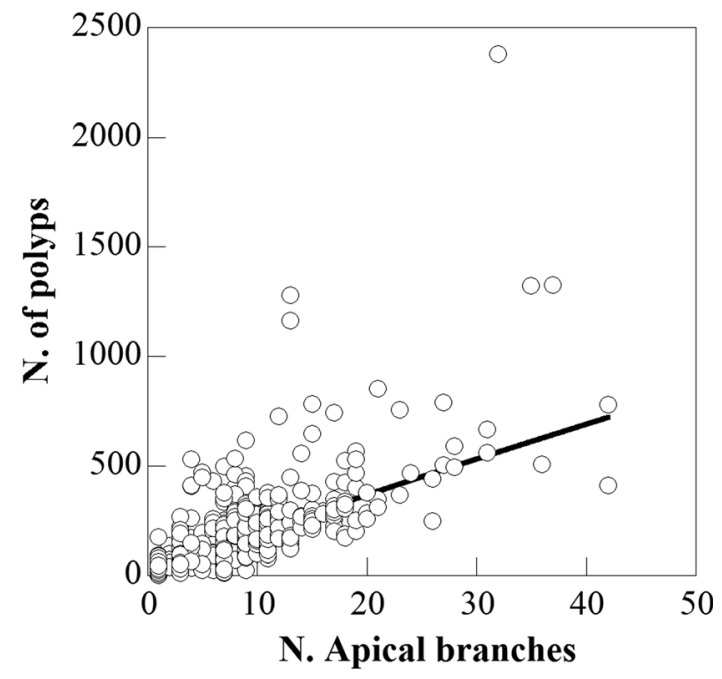

Fig. 3 Relationship between apical branch and polyp number: $\mathrm{y}=23.87 \mathrm{x}^{0.91}, R^{2}=0.62, p<0.01, \mathrm{ES}=138$

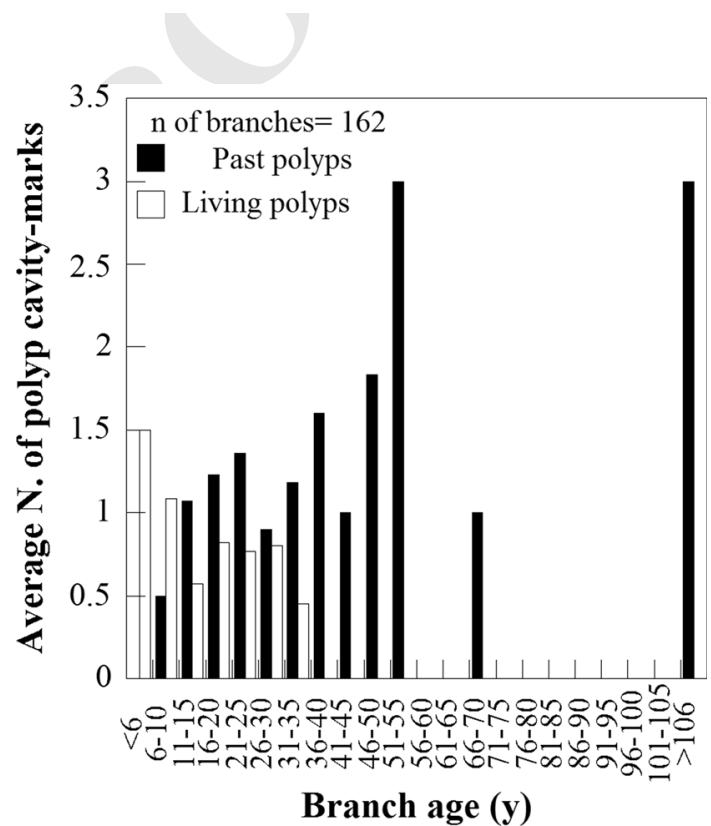

Fig. 4 Mean number of polyp cavity marks per colony branches of different age classes

colony ( $<10$ years), with their number decreasing with branch age. Only past polyp markers were found on branch sections older than 35 years (Fig. 4).

Despite the wide variability in polyp longevity, no polyp (out of the 355 examined) was older than 12 years suggesting that senescence is likely an important process in regulating polyp dynamics within colonies. The median age of past polyps and their maximum life span were 4 and 12 years, respectively ( $n=234$; Fig. 5).

As expected, living polyps were generally younger than past ones, accounting for $45 \%$ of the $<1$-year-old ones.

\begin{tabular}{|c|c|c|c|c|}
\hline & Journal : Large 338 & Dispatch & $18-5-2020$ & Pages: 12 \\
\hline & $\begin{array}{l}\text { Article No. : } 1942 \\
\text { MS Code : } \quad \text { CORE-D-18-00305R3 }\end{array}$ & $\begin{array}{l}\square \text { LE } \\
\sim_{\mathrm{CP}}\end{array}$ & & $\begin{array}{l}\square \text { TYPESET } \\
\downarrow_{\text {DISK }}\end{array}$ \\
\hline
\end{tabular}




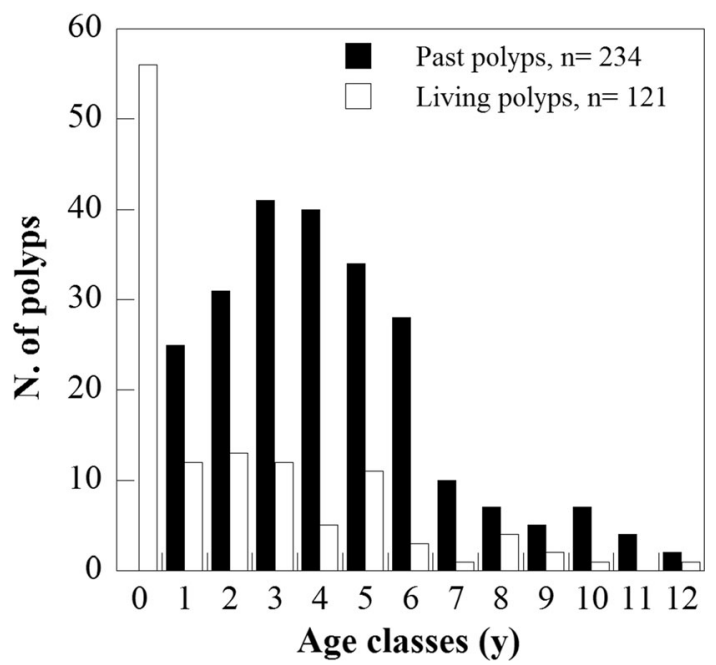

Fig. 5 Age distribution of living and past polyps
As $<1$-year-old polyps do not form cavity marks in the growth ring layer, it is not possible to individuate these polyps on the thin sections, but they can be identified only if they were alive at the time of collection through the remains of their tissue.

There was no significant difference in longevity between polyps of female and male colonies (Mann-Whitney Test, $n=82, n=93, p>0.05$ ) while polyps of deeper colonies were significantly older than those of shallow ones (5.5 vs. 4 years, Median, Mann-Whitney Test: $n=66, n=168$; $p<0.001)$.

The median diameter of cavity marks was $1.0 \mathrm{~mm}$ (C.I. $0.98-1.03 \mathrm{~mm}, n=114)$, and it is reached within the first or the second year of polyp life.

The density of polyps varied significantly among different branches (Table 1a and Fig. 6a). Post hoc tests indicated that polyp density at the apical branches $\left(16.1 \pm 1.7\right.$ polyps $\mathrm{cm}^{-2}$, Mean $\left.\pm \mathrm{ES}\right)$ was higher than at the basal branch $\left(8.0 \pm 1.2\right.$ polyps $\left.\mathrm{cm}^{-2}\right)$. Likewise, there was a trend for polyp density on internodal branches to be
Table 2 Mortality table constructed from the age at death of 234 polyps

\begin{tabular}{lrrl}
\hline Polyp age classes $(i)$ & $X_{i}$ & $S_{i}$ & $l_{i}$ \\
\hline $1-2$ & 25 & 234 & 1.00 \\
$2-3$ & 31 & 209 & 0.89 \\
$3-4$ & 41 & 178 & 0.76 \\
$4-5$ & 40 & 137 & 0.59 \\
$5-6$ & 34 & 97 & 0.41 \\
$6-7$ & 28 & 63 & 0.27 \\
$7-8$ & 10 & 35 & 0.15 \\
$8-9$ & 7 & 25 & 0.11 \\
$9-10$ & 5 & 18 & 0.08 \\
$10-11$ & 7 & 13 & 0.06 \\
$11-12$ & 4 & 6 & 0.03 \\
$12-13$ & 2 & 2 & 0.01 \\
$13-14$ & 0 & 0 & 0.00 \\
\hline$X-$ & & &
\end{tabular}

$X_{i}=$ number of polyps that died during each age interval; $S_{i}=$ number of survivors at the beginning of each age interval; $l_{i}=$ survival probability of class 1 polyps to age class $(i)$ (number of survivors as a fraction of newborns)

higher than at the base of colonies, but differences were only marginally significant. There were no differences in polyp density between internodal and apical branches (Table 1b). The linear mixed model explained about $44 \%$ of the variation in the data (conditional $R^{2}=0.436$ ), of which around $40 \%$ was explained by the fixed factor (i.e., Branch type; marginal $R^{2}=0.402$ ).

Polyp density decreased with the age of branches and higher values were found at some tips (Fig. 6b).

\section{Mortality and Budding rate}

Mortality regularly increased with polyp age and $59 \%$ of polyps died before the age of 5 years (age classes 5-6). All
360

361

362

363

364

365

366

367

368

370

371
Fig. 6 a Polyp density in different branches of the colony. Bars $=$ SE. b Polyp density versus age of basal, internodal and apical branches $(y=28.3$ $\left.11.7 \log (x), R^{2}=0.47, p<0.05\right)$
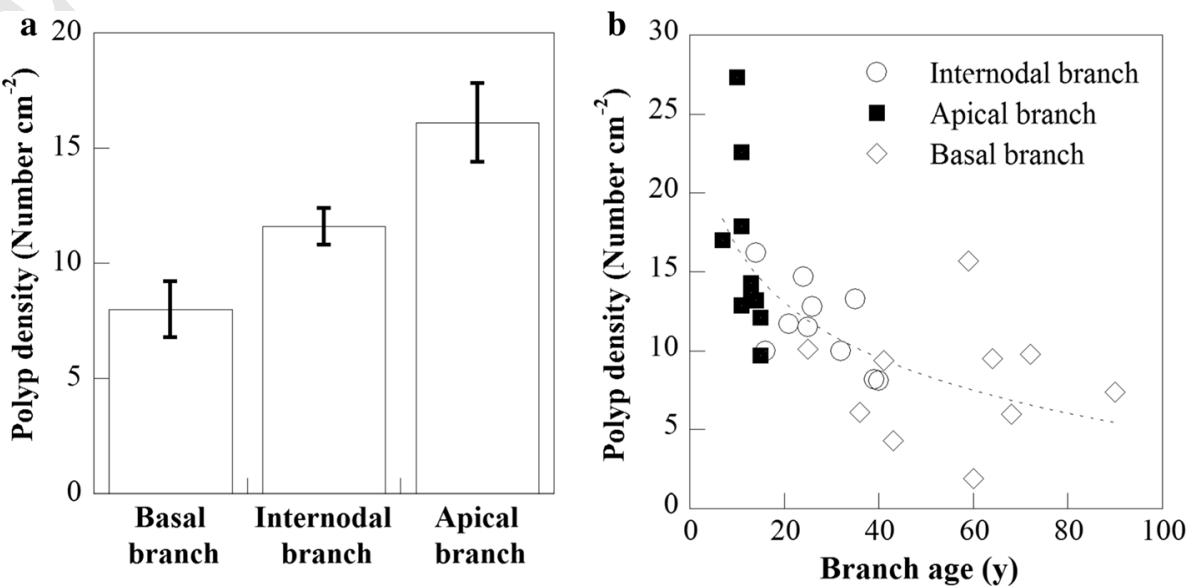

\begin{tabular}{|l|lll|}
\hline Journal : Large 338 & Dispatch : 18-5-2020 & Pages : 12 \\
& Article No. : 1942 & $\square$ LE & $\square$ TYPESET \\
& MS Code : CORE-D-18-00305R3 & $\square_{\mathrm{CP}}$ & $\checkmark$ DISK \\
\hline
\end{tabular}


Table 3 Survival transition matrix of a Corallium rubrum polyp population. The diagonal represents the portion $\left(\sigma_{i}\right)$ of polyps that raised by one class to the following each year

$\left(\begin{array}{cccccccccccc}0 & 0 & 0 & 0 & 0 & 0 & 0 & 0 & 0 & 0 & 0 & 0 \\ \mathbf{0 . 8 9} & 0 & 0 & 0 & 0 & 0 & 0 & 0 & 0 & 0 & 0 & 0 \\ 0 & \mathbf{0 . 8 5} & 0 & 0 & 0 & 0 & 0 & 0 & 0 & 0 & 0 & 0 \\ 0 & 0 & \mathbf{0 . 7 7} & 0 & 0 & 0 & 0 & 0 & 0 & 0 & 0 & 0 \\ 0 & 0 & 0 & \mathbf{0 . 7 1} & 0 & 0 & 0 & 0 & 0 & 0 & 0 & 0 \\ 0 & 0 & 0 & 0 & \mathbf{0 . 6 5} & 0 & 0 & 0 & 0 & 0 & 0 & 0 \\ 0 & 0 & 0 & 0 & 0 & \mathbf{0 . 5 6} & 0 & 0 & 0 & 0 & 0 & 0 \\ 0 & 0 & 0 & 0 & 0 & 0 & \mathbf{0 . 7 1} & 0 & 0 & 0 & 0 & 0 \\ 0 & 0 & 0 & 0 & 0 & 0 & 0 & \mathbf{0 . 7 2} & 0 & 0 & 0 & 0 \\ 0 & 0 & 0 & 0 & 0 & 0 & 0 & 0 & \mathbf{0 . 7 2} & 0 & 0 & 0 \\ 0 & 0 & 0 & 0 & 0 & 0 & 0 & 0 & 0 & \mathbf{0 . 4 6} & 0 & 0 \\ 0 & 0 & 0 & 0 & 0 & 0 & 0 & 0 & 0 & 0 & \mathbf{0 . 3 3} & 0\end{array}\right)$

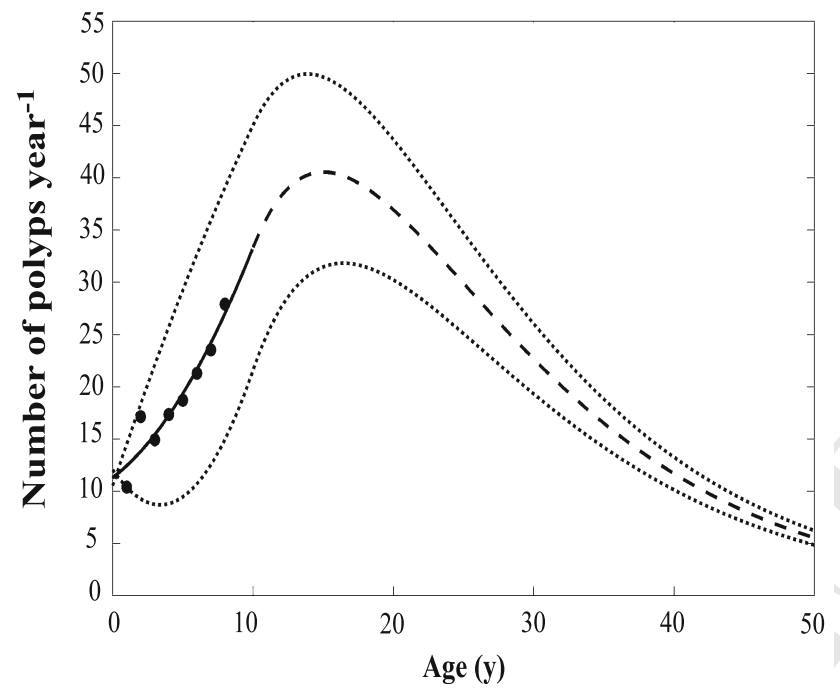

Fig. 7 Branch budding rate over time. Continuous line: values of $\beta_{n}$ (branch budding rate) for a young and unbranched colony of age ranging from 1 to 9 years (data from Bramanti et al. 2005 and Santangelo et al. 2007). Dashed line: estimated $\beta_{n}$ from 10 to 50 years. The two dotted curves represent the variability of $\beta_{n}$

polyps of a new, annual cohort (age class) died within 12 years; thus the complete turnover of a colony could occur several times during its life cycle (e.g., a colony 100 years old could renew its polyps about 8 times).

A mortality table was constructed using the age at death of past polyps (Table 2). In this table, polyps were divided into 13 yearly age classes, and the yearly number of dead $\left(X_{i}\right)$ and survivors $\left(S_{i}\right)$ were reported. The polyp mortality table was, then, used to compile a survival transition matrix which describes the portion of polyps that, for each year, passed from one age class to the following (Table 3). The matrix was then applied to develop a dynamic population model which fits the polyp budding rate of a young, unramified colony (data from the literature in Supplemental
Materials) and projects this rate up to 50 years (during this time the young colony became the basis of an older, larger one; Fig. 7). According to the model, the yearly number of polyps increases (up to 40 polyps year ${ }^{-1}$ ) with the age of branches and, after 15-16 years, it decreases reaching the lowest value $\left(<10\right.$ polyps years $\left.{ }^{-1}\right)$ at 50 years. The model is based on average values and the variability around these values was calculated as reported in Supplemental Materials and represented by dotted lines in Fig. 7 .

\section{Discussion}

Understanding the mechanisms underpinning the organization of polyps by an a posteriori demographic approach could shed some new light on the growth of long-lived, branched gorgonians. In Corallium rubrum, the colony shape may be described by a blend between the bifurcation model, in which "a single branch divides in two sisters branches" (Brazeau and Lasker 1992) and the motherdaughter branching model, in which "colonies branching subapically, generating hierarchical mother-daughter relationships among branches" (Lasker et al. 2003; Sánchez et al. 2004; among others). Simulations of the modular growth of $C$. rubrum colonies have been developed on the basis of simple stochastic rules and results suggested that the morphology can result two conflicting processes, branching and growth, priority of which is regulated by environmental factors (Kahramanoğullari et al. 2019).

In the Mediterranean red coral, the overall number of polyps is correlated with colony age during the first years of life (Bramanti et al. 2005), while in the older colonies, such as those examined here, this correlation is lost. In these larger colonies, the number of polyps is a function of the total number of apical branches that, despite the wide variability in their size, are characterized by higher polyp density. As the first ramification starts around 10 years (Benedetti et al. 2016), the lack of a correlation between polyp number and colony age in $>10$ years old colonies is likely the result of a large variation in the branching process.

While the reproductive cycle of $C$. rubrum is well known (Vighi 1972; Santangelo et al. 2003), the mechanisms regulating the production of new polyps are still poorly understood. The highly variable colony morphology recorded in several octocorals, often considered as a consequence of large variability in hydro-mechanical forces (Patterson 1980; Chindapol et al. 2013; among others), could be driven by polyp density and distribution. Perrin et al. (2015) suggested that the direction of growth of new branches in $C$. rubrum could be influenced by the position of the polyp with respect to the tip: “...radially distributed polyps could favor a uni-directional vertical growth, while
396

397

398

399

400

401

402

403

404

405

406

407

408

409

410

411

412

413

414

415

416

417

418

419

420

421

422

423

424

425

426

427

428

429

430

431

432

433

434

435

\begin{tabular}{|llll|}
\hline Journal : Large 338 & Dispatch : 18-5-2020 & Pages : 12 \\
Article No. : $\mathbf{1 9 4 2}$ & $\square$ LE & $\square$ TYPESET \\
MS Code : CORE-D-18-00305R3 & $\boldsymbol{V}_{\mathrm{CP}}$ & $\boldsymbol{\sim}$ DISK \\
\hline
\end{tabular}


polyps located at the very tip of the branch could favor the emergence of a ramification." Occasionally, some polyps can drive the growth of further secondary branches starting from the base or well below the colony tips, probably by increasing the production of sclerites at their bases (Perrin et al. 2015; Benedetti et al. 2016).

A first attempt to model the evolution over time of polyp number in a $C$. rubrum colony was recently made by Galli et al. (2016), who assumed that new polyps are produced by the older ones via a budding process that depends on the number of polyps at budding time. However, differently from scleractinians (e.g., Richmond 1997; Gateño and Rinkevich 2003) and some octocorals (Lan da Silveira and Van't Hof 1977), no budding in already existing polyps has ever been documented in C. rubrum. The only description of new polyp formation in colonies of this species dates back to about 150 years ago, when the French naturalist, Henry Lacaze Duthiers, described the "blastogenesis of a polyp" as a "small whitish tumor" appearing on a point on the colony surface (Lacaze Duthiers 1864). The lack of polyp budding in the Mediterranean red coral has been further confirmed by other researchers (S Rossi and G Tsounis, pers. comm.). In conclusion the formation of new polyps likely occurs on some points of the gastrodermal channels embedded in the coenenchyma, following modalities that are still unknown.

An analysis of the polyp distribution along colony branches of different ages may provide a proxy for the local budding rate of polyps. We found a significantly higher density of polyps at the tips that together with its decrease with increasing age suggests a higher rate of production of new polyps in the younger parts of the colony. Such observation is supported by the faster growth rates in young colonies (Bramanti et al. 2005; 2007) and at the tips (Benedetti et al. 2016; Lartaud et al. 2016). The higher polyp density found at some tips, indicating faster growth in some branches, could lead to directional and asymmetrical colony growth.

At the base of branched colonies, polyp density and diameter growth rates are lower and vertical growth stops (Bramanti et al. 2014; Benedetti et al. 2016). The small number of polyps found in this portion of the colony could be explained by the limited plankton supply due to the reduced current and the trophic shadow cast by higher rank branches (Kim and Lasker 1997). We should then expect that the sparse polyps found at the colony base may either change their tentacles in response to a lower food supply (Abel 1970; Lopez-Gonzalez et al. 2018) or shift from a trophic to a cleaning/sweeping function.

Little is known about the life cycle of coral polyps. The literature data are highly variable, spanning between the observation made by Beklemishev (1969) who described the polyps of colonial anthozoans as "short-lived," and the reports of Wood-Jones (1907) who believed that coral polyps were theoretically immortal. In a more recent study on scleractinian polyps, Darke and Barnes (1993) estimated a mean polyp life expectancy of 5 years and a maximum life span of 8 years. Moreover, they found a significant difference in polyp longevity between colonies collected on reefs characterized by different "bumpiness" (i.e., lenticular growth surface; Darke and Barnes 1993). To date, measures of polyp life span in gorgonian corals are rare. In the Mediterranean red coral, Vielzeuf et al. (2008) report that "...a polyp appears, fulfills its functions, and then disappears after 6-8 years of activity." Using the method described in the foregoing, we determined the age distribution of polyps in $C$. rubrum colonies collected from different geographic areas and depths. According to our results, $C$. rubrum polyps reach their maximum size in the first two years of life and have an average life span of 4 years, with no difference between females and males, suggesting that the different time needed for female and male gonad maturation (two and one year respectively; Vighi 1972) does not influence polyp life span. Fifty-nine percent of new polyps died before 5 years and their maximum life span was 12 years. A 100-year-old colony should then pass through approximately 8 generations of polyps: such polyp renewal could be a key factor in the longevity of this species. In all colonies collected in the different sampling areas, no polyp lived more than 12 years, polyp density decreased with branch age and mortality increased with polyp age: these findings clearly suggest the relevance of polyp senescence in determining colony growth and longevity. However, this does not exclude local, partial mortality due to predation (Priori et al. 2015).

Our data indicate a significantly greater polyp age in colonies collected in deeper (50-130 m depth) than shallower areas (30-35 m depth). This difference is likely due to the higher mean colony age found in deeper populations (Tsounis et al. 2006a; Priori et al. 2013; Bramanti et al. 2014; Benedetti et al. 2016). As observed in several marine modular organisms (Sánchez et al. 2004 and references herein), the polyp budding rate in $C$. rubrum decreases with branch age. Given that colony growth rate and polyp production are higher during the first years of colony life (Bramanti et al. 2005, 2014), it was expected that polyp production would be faster in younger and less branched colonies with respect to older ones.

Using the mortality table of polyps, a transition matrix and a dynamic population model were set out to represent the branch budding rate of polyps over a life span of 50 years. In a young, unbranched colony, the branch budding rate increases up to 15 years of life, to decrease in the following period, when the formerly young colony becomes the basis of an older, branched one. Such bell- 
shaped trend is consistent with the reduction of polyp density observed in the older parts of a colony, likely due to senescence.

The demographic model proposed in this paper describes the modular growth of young, unbranched $C$. rubrum colonies. Our findings represent a first step toward the development of advanced polyp dynamic models aimed at representing the complex growth of older, ramified colonies, in which also the second factor of modularity (i.e. the branching process) and the variability of the growth process, should be included.

Acknowledgements We would like to thank A. Malasoma and A. Bernardeschi (TS Lab \& Geoservices snc of Pisa) for their help in preparing the red coral thin sections. We also wish to thank G. Galli (Plymouth Marine Laboratory and Istituto Nazionale di Oceanografia e Geofisica Sperimentale, Trieste) for his intriguing questions on polyp life cycle, D. Vielzeuf (CINaM - Centre Interdisciplinaire de Nanoscience de Marseille) for his useful suggestions on the manuscript, and A. Cafazzo for his revision of the English text. This work is part of the PhD Thesis of M.C. Benedetti, which has been funded by Enzo Liverino s.r.l., Chii Lih Coral Co Ltd of Taiwan and the University of Pisa.

\section{References}

Abel EF (1970) Über den Tentakelapparat der Edelkoralle (Corallium rubrum L.) und seine Funktion beim Beutefangverhalten. Oecologia 4:133-142

Arrigoni M, Manfredi P, Panigada S, Bramanti L, Santangelo G (2011) Life-history tables of the Mediterranean fin whale from stranding data. Mar Ecol 32:1-9

Barham E, Davies IE (1968) Gorgonian and water motion studies in the Gulf of California. Underwater Naturalist 5:24-28

Barton K (2019) Package 'MuMIn'. R package version, 1.43.15. https://CRAN.R-project.org/package=MuMIn

Bates D, Maechler M, Bolker B, Walker S, Christensen RHB, Singmann H, Dai B, Grothendieck G, Green P (2015) Package 'lme4'. Convergence, 12

Beklemishev WN (1969) Principles of comparative anatomy of invertebrates. Oliver \& Boyd, Edinburgh

Benedetti MC, Priori C, Erra F, Santangelo G (2016) Growth patterns in mesophotic octocorals: timing the branching process in the highly-valuable Mediterranean Corallium rubrum. Estuar Coast Shelf Sci 171:106-110

Bergher J (1990) Persistence of different-sized populations: an empirical assessment of rapid extinction in bighorn sheep. Conservation Biology 4:91-98

Bramanti L, Magagnini G, De Maio L, Santangelo G (2005) Recruitment, early survival and growth of the Mediterranean red coral Corallium rubrum (L 1758), a 4-year study. J Exp Mar Bio Ecol 314:69-78

Bramanti L, Rossi S, Tsounis G, Gili JM, Santangelo G (2007) Settlement and early survival of red coral on artificial substrates in different geographic areas: some clues for demography and restoration. Hydrobiologia 580:219-224

Bramanti L, Iannelli M, Santangelo G (2009) Mathematical modelling for conservation and management of gorgonians corals: youngs and olds, could they coexist? Ecol Model 220:2851-2856
Bramanti L, Vielmini I, Rossi S, Tsounis G, Iannelli M, CattaneoVietti R, Priori C, Santangelo G (2014) Demographic parameters of two populations of red coral (Corallium rubrum L. 1758) in the North Western Mediterranean. Mar Biol 161:1015-1026

Bramanti L, Benedetti MC, Cupido R, Cocito S, Priori C, Erra F, Iannelli M, Santangelo G (2017) Demography of animal forests: the example of mediterranean gorgonians. In: Rossi S, Bramanti L, Gori A, Orejas C (eds) Marine animal forests. Springer international publisher, pp 1-20

Brazeau DA, Lasker HR (1992) Growth rates and growth strategy in a clonal marine invertebrate, the Caribbean octocoral Briareum asbestinum. Biol Bull 183:269-277

Burlando B, Cattaneo-Vietti R, Parodi R, Scardi M (1991) Emerging fractal properties in gorgonian growth forms (Cnidaria: octocorallia). Growth Dev Aging 55:161-168

Caswell H (2001) Matrix population models: construction, analysis and interpretation, 2nd edn. Sinauer Associates, Sunderland, Massachusetts

Cau A, Bramanti L, Cannas R, Follesa MC, Angiolillo M, Canese SP, Bo M, Cucco D, Guizien K (2016) Habitat constraints and selfthinning shape Mediterranean red coral deep population structure: Implications for conservation practice. Sci Rep 6

Chindapol N, Kaandorp JA, Cronemberger C, Mass T, Genin A (2013) Modelling growth and form of the scleractinian coral Pocillopora verrucosa and the influence of hydrodynamics. PLoS Comput Biol 9:e1002849

Cicogna F, Cattaneo-Vietti R (1993) Red coral in the Mediterranean Sea, art, history and science. Ministero Risorse Agricole, Alimentari e Forestali, Roma

Coma R, Ribes M, Gili JM, Hughes RN (2001) The ultimate opportunists: consumers of seston. Mar Ecol Prog Ser 219:305-308

Costantini F, Rossi S, Pintus E, Cerrano C, Gili JM, Abbiati M (2011) Low connectivity and declining genetic variability along a depth gradient in Corallium rubrum populations. Coral reefs 30:991-1003

Darke WM, Barnes DJ (1993) Growth trajectories of corallites and ages of polyps in massive colonies of reef-building corals of the genus Porites. Mar Biol 117:321-326

Fujiwara M, Caswell H (2001) Demography of endangered North Atlantic right whale. Nature 414:537-541

Galli G, Bramanti L, Priori C, Rossi S, Santangelo G, Tsounis G, Solidoro C (2016) Modelling red coral (Corallium rubrum) growth in response to temperature and nutrition. Ecol Modell 337:137-148

Gallmetzer I, Haselmai A, Velimirov B (2010) Slow growth and early sexual maturity: bane and boon for the red coral Corallium rubrum. Estuar Coast Shelf Sci 90:1-10

Garrabou J, Sala E, Linares C, Ledoux JB, Montero-Serra I, Dominici JM, Kipson S, Teixidò N, Cebrian E, Kersting DK, Harmelin JG (2017) Re-shifting the ecological baseline for the overexploited Mediterranean red coral. Sci Rep 7:42404

Gateño D, Rinkevich B (2003) Coral polyp budding is probably promoted by a canalized ratio of two morphometric fields. Mar Biol 142:971-973

General Fisheries Commission for the Mediterranean Scientific Advisory Committee, GFCM-FAO (2011) Report of the second transversal workshop on red coral. Ajaccio, Corsica, France, 5-7 October 2011

Goffredo S, Lasker HR (2006) Modular growth of a gorgonian coral can generate predictable patterns of colony growth. Estuar Coast Shelf Sci 336:221-229

Gori A, Rossi S, Linares S, Berganzo E, Orejas C, Dale MRT, Gili JM (2011) Size and spatial structure in deep versus shallow population of the Mediterranean gorgonian Eunicella singularis

\begin{tabular}{|l|ll|}
\hline Journal : Large 338 & Dispatch : 18-5-2020 & Pages : 12 \\
Article No. : 1942 & $\square$ LE & $\square$ TYPESET \\
MS Code : CORE-D-18-00305R3 & $\checkmark$ CP & $\checkmark$ DISK \\
\hline
\end{tabular}


(Cap de Creus, northwestern Mediterranean Sea). Mar Biol 158:1721-1732

Grigg RW (1972) Orientation and growth form of sea fans. Limnol Oceanogr 17:185-192

Grillo MC, Goldberg WM, Allemand D (1993) Skeleton and sclerite formation in the precious red coral, Corallium rubrum. Mar Biol 117:119-128

Guizien K, Ghisalberti M (2017) Living in the canopy of the animal forest: physical and biogeochemical aspects. In: Rossi $\mathrm{S}$, Bramanti L, Gori A, Orejas C (eds) Marine animal forests. Springer international publisher, pp 507-528

Hageman SJ (2003) Complexity generated by iteration of hierarchical modules in Bryozoa. Integr Comp Biol 43:87-98

Hageman SJ, Bock PE, Bone Y, Mcgowran B (1998) Bryozoan growth habits: classification and analysis. J Paleontol 72:418-436

Harper JL (1977) Population biology of plants. Academic press, London

Harper JL, Bell AD (1979) The population dynamics of growth form in organisms with modular construction. In: Anderson RM, Turner BD, Taylor LP (eds) population dynamics. Blackwell Science Publisher, London, pp 29-52

Kaandorp JA, Küler JE (2001) The algorithmic beauty of seaweeds, sponges and corals. Springer, Berlin

Kahramanoğullari O, Bramanti L, Benedetti MC (2019) Stochastic Mechanisms of Growth and Branching in the Mediterranean Coral Colonies. International Conference on Theory and Practice of Natural Computing. Springer, Cham, pp 57-69

Kim K, Lasker HR (1997) Flow-mediated resource competition in the suspension feeding gorgonian Plexaura homomalla (Esper). J Exp Mar Biol Ecol 215:49-64

Kim K, Lasker HR (1998) Allometry of resource capture in colonial cnidarians and constraints on modular growth. Funct Ecol 12:646-654

Knittweis L, Aguilar R, Alvarez H, Borg JA, Evans J, Garcia S, Schembri PJ (2016) New depth record of the precious red coral Corallium rubrum for the Mediterranean. Rapport de la Commission internationale de la Mer Méditerranée 41

Kuznetsova A, Brockhoff PB, Christensen RHB (2017) LmerTest package: Tests in linear mixed effects models. J. Stat. Softw. 82: 1-26. https://doi.org/10.18637/jss.v082.i13

Lacaze Duthiers H (1864) Histoire naturelle du corail, Paris

Lan da Silveira F, Van't Hof T (1977) Regeneration in Plexaura. Bijdragen tot de dierkunde 47:98-108

Lasker HR, Boller ML, Castanaro J, Sanchez JA (2003) Determinate growth and modularity in a gorgonian octocoral. Biol Bull 205:319-330

Lartaud F, Galli G, Raza A, Priori C, Benedetti MC, Cau A, Santangelo G, Iannelli M, Solidoro C, Bramanti L (2016) Growth patterns in long-lived animals. In: Rossi S, Bramanti L, Gori A, Orejas C (eds) Marine animal forests. Springer international publisher, pp 595-626

Lenth RV (2016) Least-squares means: the R package 1smeans. Journal of statistical software 69:1-33

Lopez-Gonzalez P, Bramanti L, Escribano-Álvarez P, Benedetti MC, Martínez-Baraldés I, Megina C (2018) Thread-like tentacles in the Mediterranean corals Paramuricea clavata and Corallium rubrum. Mediterr. Mar, Scie

Marschal C, Garrabou J, Harmelin JG, Pichon M (2004) A new method for measuring growth and age in the precious red coral Corallium rubrum (L.). Coral Reefs 23:423-432

Matsumoto AK (2004) Heterogeneous and compensatory growth in Melithaea flabellifera (Octocorallia: melithaeidae) in Japan. Hydrobiologia 530:389-397

Merks RMH, Hoekstra AG, Kaandora JA, Sloot PMA (2004) Polyp oriented modelling of coral growth. J Theor Biol 228:559-576
Nakagawa S, Schielzeth H (2013) A general and simple method for obtaining $R^{2}$ from generalized linear mixed-effects models. Methods Ecol. Evol. 4:133-142

Patterson MR (1980) Hydromechanical adaptations in Alcyonium sidereum (Octocorallia). In: Schneck DJ (ed) Biofluid Mechanics 2. Springer, Boston MA, pp 183-201

Pedoni C, Follesa MC, Cannas R, Matta G, Pesci P, Cau A (2009) Preliminary data on red coral (Corallium rubrum) population of Sardinian Sea (Western Mediterranean). In: UNEP-MAP-RAC/ SPA, Proceedings of the 1st symposium on conservation of the coralligenous bio-concretions. Pergent-Martini C, Brichet (eds) RAC/SPA publ. Tunis

Perrin J, Vielzeuf D, Ricolleau A, Dallaporta H, Valton S, Floquet N (2015) Block-by-block and layer-by-layer growth modes in coral skeletons. Am Mineral 100:681-695

Picciano M, Ferrier-Pagès C (2007) Ingestion of pico-and nanoplankton by the Mediterranean red coral Corallium rubrum. Mar Biol 150:773-782

Priori C, Mastascusa V, Erra F, Angiolillo M, Canese S, Santangelo G (2013) Demography of deep-dwelling red coral populations: age and reproductive structure of a highly valued marine species. Estuar Coast Shelf Sci 118:43-49

Priori C, Erra F, Angiolillo M, Santangelo G (2015) Effects of gastropod predation on the reproductive output of an overexploited deep octocoral. Coral Reefs 34:59-63

Richmond RH (1997) Reproduction and recruitment in corals: critical links in the persistence of reefs. In: Birkeland C (ed) Life and death of coral reefs. Chapman \& Hall, New York, pp 175-197

Rosen BR (1986) Modular growth and form of corals: a matter of metamers? Philos Trans R Soc Lond B Biol Sci 313:115-142

Rossi S, Rizzo L, Duchêne J (2019) Polyp expansion of passive suspension feeders: a red coral case study. PeerJ Preprints 7:e27490v1

Rowley SJ, Pochon X, Watling L (2015) Environmental influences on the Indo-Pacific octocoral Isis hippuris Linnaeus 1758 (Alcyonacea: isididae): genetic fixation or phenotypic plasticity? PeerJ 3:e1128

Russo AR (1985) Ecological observations on the gorgonian sea fan Eunicella cavolinii in the Bay of Naples. Mar Ecol Prog Ser 24:155-159

Sánchez JA, Lasker HR (2003) Patterns of morphological integration in marine modular organisms: supra-module organization in branching octocoral colonies. Proc R Soc Lond B Biol Sci 270:2039-2044

Sánchez JA, Lasker HR, Nepomuceno EG, Sánchez JD, Woldenberg MJ (2004) Branching and self-organization in marine modular colonial organisms: a model. Am. Nat. 163:24-39

Sánchez JA, Aguilar C, Dorado D, Manrique N (2007) Phenotypic plasticity and morphological integration in a marine modular invertebrate. BMC Evolutionary Biology 7:122

Santangelo G, Abbiati M (2001) Red coral: conservation and management of an over-exploited Mediterranean species. Aquat Conserv 11:253-259

Santangelo G, Carletti E, Maggi E, Bramanti L (2003) Reproduction and population sexual structure of the overexploited Mediterranean red coral Corallium rubrum. Mar Ecol Prog Ser 248:99-108

Santangelo G, Bramanti L, Iannelli M (2007) Population dynamics and conservation biology of the over-exploited Mediterranean red coral. J Theor Biol 244:416-423

Santangelo G, Cupido R, Cocito S, Bramanti L, Priori C, Erra F, Iannelli M (2015) Effects of increased mortality on gorgonian corals (Cnidaria, Octocorallia): different demographic features may lead affected populations to unexpected recovery and new equilibrium points. Hydrobiologia 759:171-187 
Shaish L, Abelson A, Rinkevich B (2006) Branch to colony trajectory in a modular organism: pattern formation in the Indo-Pacific coral Stylophora pistillata. Dev Dyn 235:2111-2121

Shaish L, Abelson A, Rinkevich B (2007) How Plastic Can Phenotypic Plasticity Be? The Branching Coral Stylophora pistillata as a Model System. PLoS ONE 2:e644

Sherwood OA (2006) Deep-sea octocorals: dating methods, stable isotopic composition, and proxy records of the slopewaters off Nova Scotia. PhD Thesis, Dalhousie University Halifax, Nova Scotia

Thresher RE, MacRae CM, Wilson NC, Fallon S (2009) Feasibility of age determination of deep-water bamboo corals (Gorgonacea; Isididae) from annual cycles in skeletal composition. Deep Sea Res Part 1 Oceanogr Res Pap 56: 442-449

Tsounis G, Rossi S, Gili JM, Arntz W (2006a) a) Population structure of an exploited benthic cnidarian: the case study of red coral (Corallium rubrum L.). Mar Biol 149:1059-1070

Tsounis G, Rossi S, Laudien J, Bramanti L, Fernandez N, Gili JM, Arntz W (2006b) b) Diet and seasonal prey capture rates in the
Mediterranean red coral (Corallium rubrum L.). Mar Biol 149:313-325

Tsounis G, Rossi S, Grigg R, Santangelo G, Bramanti L, Gili JM (2010) The exploitation and conservation of precious corals. Oceanography And Marine Biology; An Annual Review 48:161-212

Vielzeuf D, Garrabou J, Baronnet A, Grauby O, Marschal C (2008) Nano to macroscale biomineral architecture of red coral (Corallium rubrum). Am Mineral 93:1799-1815

Vighi M (1972) Etude sur la reproduction du Corallium rubrum. Vie Milieu 23:21-32

Williams GS (1975) The strawberry coral model. In: Sex and evolution. Princeton, NJ: Princeton University Press

Wood-Jones F (1907) On the growth forms and supposed species in corals. Proceedings of the Zoological Society of London 77:518-556

Publisher's Note Springer Nature remains neutral with regard to jurisdictional claims in published maps and institutional affiliations.

\begin{tabular}{|lll|} 
Journal : Large 338 & Dispatch : 18-5-2020 & Pages : 12 \\
Article No. : $\mathbf{1 9 4 2}$ & $\square$ LE & $\square$ TYPESET \\
MS Code : CORE-D-18-00305R3 & $\sim_{\text {CP }}$ & $\checkmark$ DISK \\
\hline
\end{tabular}

